\title{
A Liquid Chromatography/Tandem Mass Spectrometric Method for Determination of Captopril in Human Plasma: Application to a Bioequivalence Study
}

\author{
Eman S. Elzanfaly ${ }^{1,2}$, Hanan A. Merey ${ }^{1 *}$ \\ ${ }^{1}$ Analytical Chemistry Department, Faculty of Pharmacy, Cairo University, Kasr-El-Aini 11562-Cairo, Egypt \\ ${ }^{2}$ Center of Applied Research and Advanced Studies, Faculty of Pharmacy, Cairo University, Cairo, Egypt.
}

\begin{tabular}{|c|c|}
\hline ARTICLE INFO & ABSTRACT \\
\hline $\begin{array}{l}\text { Article history: } \\
\text { Received on: } 12 / 10 / 2016 \\
\text { Accepted on: } 15 / 11 / 2016 \\
\text { Available online: } 27 / 02 / 2017\end{array}$ & $\begin{array}{l}\text { A simple, rapid and sensitive ultra-performance liquid chromatography/positive ion electrospray tandem mass } \\
\text { spectrometric method was developed and validated for the quantification of captopril in human plasma. } \\
\text { Following plasma protein precipitation, the analyte and internal standard Rosuvastatin were separated by ultra- } \\
\text { performance liquid chromatography using a gradient mode mobile phase on a reversed-phase column and }\end{array}$ \\
\hline $\begin{array}{l}\text { Key words: } \\
\text { Captopril, liquid } \\
\text { chromatography, mass } \\
\text { spectrometry, human plasma, } \\
\text { protein precipitation. }\end{array}$ & $\begin{array}{l}\text { ions, } \mathrm{m} / \mathrm{z} 218.09 / 116.16 \text { for captopril and } \mathrm{m} / \mathrm{z} 482.2 / 258.17 \text { for the internal standard. The method exhibited a } \\
\text { linear dynamic range of } 10-2000 \mathrm{ng} / \mathrm{mL} \text { for captopril in human plasma. The lower limit of quantification } \\
\text { was } 10 \mathrm{ng} / \mathrm{mL} \text { with a relative standard deviation of less than } 6 \% \text {. Acceptable precision and accuracy were } \\
\text { obtained for concentrations over the standard curve range. A total run time of } 3 \text { minutes for each sample made it } \\
\text { possible to analyze more than } 20 \text { human plasma samples per one hour. The validated method has been } \\
\text { successfully applied to analyze human plasma samples in a bioequivalence study of captopril after oral } \\
\text { administration of } 50 \mathrm{mg} \text { captopril tablet to } 24 \text { healthy subjects. }\end{array}$ \\
\hline
\end{tabular}

\section{INTRODUCTION}

Captopril (CAP) Fig 1, (S)-1-(3-mercapto-2-methyl-1oxo propyl)-L- proline is an orally active angiotensin-converting enzyme inhibitor widely used in the treatment of hypertension , congestive heart failure and in left ventricular dysfunction after myocardial infarction and diabetic nephropathy (Physicians, 2003). Development of bioanalytical methods for drugs possessing free sulfhydral group (-SH) groups such as captopril, is considered a challenging task due to the extreme reactivity of this group. The free sulfhydral group (-SH) in captopril binds readily to albumin and other plasma proteins. It also forms disulphides with endogeneous thiol-containing compounds (cysteine, glutathione), as well as disulphide dimmer of parent compound (Klein et al., 1990; Srinivas and Mamidi, 2003). Only the free captopril is pharmacologically active and the formation

* Corresponding Author

Email: hanan.merey@pharma.cu.edu.eg of the inactive disulfides is reversible; hence, they may act as a reservoir for free captopril and thus contribute to a longer duration of the action than predicted by blood concentrations of free captopril (Duchin et al., 1988). As a consequence, the total captopril plasma concentration is probably an important parameter in relation to therapeutic effect. To measure the total captopril plasma level, two approaches were usually used. The first approach was to stabilize the $\mathrm{SH}$ group in the biosamples, immediately after collection, to prevent conversion of thiol compounds into the respective disulfides and/or mixed disulfides using several stabilizing agents such as N-(1-pyrenyl) maleimide (Rezende et al., 2007), N-ethylmaleimide (NEM) (Chik et al., 2014), p-bromo-phenacyl bromide (p-BPB) (Huang et al., 2006; Jankowski et al., 1995; Rezende et al., 2007; Vancea et al., 2009), monobrombimane (Kok et al., 1997; Tache et al., 2002), 2-bromo 2-acetonaphtone (Foroutan et al., 2003), o-phthaldialdehyde (Hadjmohammadi et al., 2008; Kok et al., 1997) and 1-benzyl-2chloropyridinium bromide (Bald and Sypniewski, 1997; Bald et al., 1996). 
The other approach depends on the reversibility of the formed disulphides so the methods utilizing this approach involves reduction of the disulphide bond after its formation with agents such dithiothreitol (DTT) (Borges et al., 2006; Rezende et al., 2007; Salem et al., 2005) to revert the converted disulphides dimmer (or conjugates) into captopril, as well as to prevent the formation of the disulphides dimmers during the sample preparation and analysis.

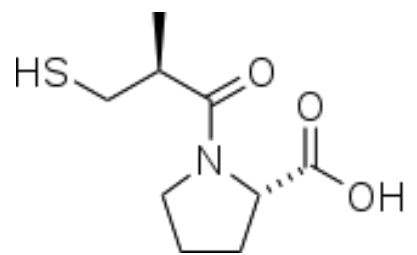

Fig. 1: Chemical structure of captopril.

Several liquid chromatographic methods were applied for determination of captopril in plasma using UV detection, (Bald and Sypniewski, 1997; Bald et al., 1996; Ding et al., 2001; Foroutan et al., 2003; Hadjmohammadi et al., 2008; Huang et al., 2006; Jankowski et al., 1995; Li et al., 1996 ; Sultan et al., 2013; Sypniewski and Bald, 1996) fluorescence detection (Aykin et al., 2001; Kok et al., 1997; Tache et al., 2002) or mass detection (Borges et al., 2006; Chik Z et al., 2014; Du, 2007; Rezende et al., 2007; Salem et al., 2005; Vancea et al., 2009) using either protein precipitation, solid phase extraction or liquid- liquid extraction for sample preparation prior to analysis.

Sample preparation is a key element in bioanalytical method development that leads to improved selectivity and sensitivity. It removes interfering matrix compounds in the sample, to reduce the risk of matrix effects in LC/MS procedures. The most widely used techniques for biological samples are solid phase extraction, liquid liquid extraction and protein precipitation. In spite of that the prepared samples are not as clean as the two other methods; protein precipitation is the simplest, fastest and cheapest means of bioanalytical sample pre-treatment especially when large number of samples is to be analyzed. It only involves the addition of a precipitating solvent, subsequent homogenization and centrifugation. The bioanalytical part of a bioequivalence study requires an analytical method with simplicity, selectivity, sensitivity and high throughput. The aim of this work was to develop and validate an improved simple, high throughput liquid chromatography/tandem mass spectrometry (LC-MS/MS) bioanalytical method for determination of captopril in human plasma using the simplest method of sample preparation, ecofriendly solvents and a short runtime to be suitable for the large amount of samples involved in bioequivalence studies.

\section{EXPERIMENTAL}

\section{Chemicals}

Captopril, B.N. 3010065 was obtained from Alexndria Co. for Pharmaceuticals and Chemical Industries, (Alexandria, Egypt). Its purity was certified to be $99.98 \%$. The internal standard
Rosuvastatin (IS) (in the form of calcium salt), B.N. OP-23/GVG (60) 96 was obtained and certified to be $99.2 \%$ by Aqa international OPTIMUS DRUGS (P) LIMITED, India. Methanol and formic acid HPLC grade were supplied by Sigma Aldrich (St. Louis, USA). Water HPLC grade was supplied by Merck Millipore, (Darmstadt, Germany). 1,4-Dithio-DL-threitol (DTT), 98\% lot number 10186477 was purchased from Alfa Aesar GmbH \& Co (Germany). The human plasma was obtained from VACSERA (Cairo, Egypt)

\section{LC-MS/MS instrument and conditions}

Waters Aquity ${ }^{\mathrm{TM}}$ Ultra Performance LC (UPLC), binary solvent manager connected to a Waters Aquity ${ }^{\mathrm{TM}}$ Ultra Performance LC sample manager autosampler. Separation was performed on a reversed-phase column (Acquity UPLC BEH shield RP $1.7 \mu \mathrm{m}, 2.1$ x $150 \mathrm{~mm}$ ). The gradient mobile phase consisted of methanol: water containing 0.1\% Formic acid (10: 90 $\mathrm{v} / \mathrm{v}$ for $1 \mathrm{~min}$ then 95: $5 \mathrm{v} / \mathrm{v}$ till the end of the run). The gradient chromatographic separation was performed at room temperature at a flow rate of $0.3 \mathrm{~mL} / \mathrm{min}$. Each component of the mobile phase was degassed before use in a sonicator (Crest ultrasonic $500 \mathrm{D}$ Malaysia) for 10 minutes. Mass spectrometric detection was performed on Waters Aquity ${ }^{\mathrm{TM}}$ TQD (triple quad detector) MS/MS using multiple reactions monitoring (MRM). An electrospray ionization (ESI) interface in positive ionization mode was used. The main working parameters of the mass spectrometer are summarized in Table 1. Data acquisition and data integration were done using MassLynx 4.1 SCN805 Software solutions.

Table 1. Main working parameters of the tandem mass spectrometer.

\begin{tabular}{ll}
\hline Parameter & Value \\
\hline Source temperature $\left({ }^{\circ} \mathrm{C}\right)$ & 150 \\
Dwell time per transition ( second) & 0.146 \\
Capillary $(\mathrm{kV})$ & 3.00 \\
Desolvation temperature $\left({ }^{\circ} \mathrm{C}\right)$ & 400 \\
Desolvation gas flow $(\mathrm{L} / \mathrm{Hr})$ & 800 \\
Cone $(\mathrm{V})$ & Captopril: 20 , Rosuvastatin: 55 \\
Collision energy $(\mathrm{V})$ & Captopril: 15 , Rosuvastatin: 35 \\
Mode of analysis & Positive \\
Ion transition for captopril (Da) & $\mathrm{m} / \mathrm{z} 218.09 / 116.16$ \\
Ion transition for rosuvastatin (IS) (Da) & $\mathrm{m} / \mathrm{z} 482.2 / 258.17$ \\
\hline
\end{tabular}

\section{Standard solutions and quality control samples}

Standard stock solutions of captopril $(100 \mu \mathrm{g} / \mathrm{mL})$ and the IS $(100 \mu \mathrm{g} / \mathrm{mL})$ were separately prepared in methanol. Working solutions for calibration and controls were prepared by appropriate dilution in methanol. The IS working solution $(3 \mu \mathrm{g} / \mathrm{mL})$ was prepared by diluting its stock solution with methanol. Nine calibration working solutions of 100-20000 ng/mL captopril were then obtained by diluting specific volumes of stock solution with methanol. Then $50 \mu \mathrm{L}$ from these working solutions were used to spike $450 \mu \mathrm{L}$ blank plasma thus providing 9 plasma standards with the concentrations ranging from 10 to $2000 \mathrm{ng} / \mathrm{mL}$. Quality control (QC) samples with concentrations $10 \mathrm{ng} / \mathrm{mL}$ (lower limit of quantification LLOQ) $30 \mathrm{ng} / \mathrm{mL}$ (QCL), $800 \mathrm{ng} / \mathrm{mL}$ (QCM) and $1600 \mathrm{ng} / \mathrm{mL}(\mathrm{QCH})$ were used during validation and clinical samples analysis. 


\section{Plasma sample preparation}

A plasma sample $(500 \mu \mathrm{L})$ was pipetted into a $15-\mathrm{mL}$ glass tube and then $50 \mu \mathrm{L}$ of IS working solution $(3 \mu \mathrm{g} / \mathrm{mL}), 50$ $\mu \mathrm{L}$ of $200 \mathrm{mM}$ DTT in water (should be used within 2 hours from preparation) and $50 \mu \mathrm{L}$ of $1 \%$ formic acid were added. The solution was vortexed for 30 seconds then $1500 \mu \mathrm{L}$ methanol was added. The solution mixture was vortexed for 60 seconds and centrifugated for 7 minutes at $3000 \mathrm{rpm}$. A part of the clear supernatant was transferred to glass vials and put on the rack of the auto-sampler kept at $25{ }^{\circ} \mathrm{C}$. Ten microliters of the solution were injected and detected in the LC-MS/MS system.

\section{Bioanalytical method validation}

Method validation was performed according to the FDA Guidance for Industry Bioanalytical Method Validation. (FDA, 2001)

\section{Selectivity}

To check the selectivity of the method, six plasma samples (blanks) were chromatographed to be sure that there is no interference from any endogenous components with Captopril or IS in the lots of human plasma used for the preparation of calibration standards and quality control samples. The blank plasma samples were collected on the day of the study before drug administration to ensure the absence of any interference at the analyte and IS retention time or $m / z$.

\section{Linearity and range}

Linearity of the method was done on nine non-zero samples covering the total range $10-2000 \mathrm{ng} / \mathrm{mL}$ captopril+. To ensure the absence of interferences, a blank sample (a plasma sample processed without captopril or the IS), a zero sample (a plasma processed with the IS only) were also processed and analyzed. These two samples were not used to construct the calibration curve. The calibration curves were constructed using the analyte to IS peak area ratios by least-squares linear regression on consecutive days.

\section{Lower limit of quantification (LLOQ)}

The lowest calibration standard with an accuracy of $80-$ $120 \%$ and precision less than $20 \%$ coefficient of variation (CV) was established as LLOQ. The signal to noise ratio of the LLOQ signal should not be less than 10 .

\section{Precision and accuracy}

Precision and Accuracy of the method were checked by determining QC samples at the concentrations mentioned under standard solutions and quality control samples.

Six samples of each QC concentration were processed and analyzed on the same day (to evaluate intra-day precision and accuracy) or analyzed on different days (to evaluate inter-day precision and accuracy) Percent accuracy was determined by: $[($ mean found concentration $) /$ (nominal concentration $)] \times 100$. \% $\mathrm{CV}$ was calculated to express precision.

\section{Recovery}

The validity of extraction procedure was done by comparing the recovery of captopril in spiked plasma samples that were exposed to the whole extraction procedure (pre-extraction samples) with the peak area of captopril in samples spiked at the end of the extraction procedure (post extraction samples). Three concentrations (each of low, medium and high QCs) were used for this purpose.

\section{Stability of the analytes}

Four levels were used to check the stability of the analytes in human plasma: Short term stability at room temperature, post-preparative stability in the autosampler, freezethaw stability and long-term stability at $-85^{\circ} \mathrm{C}$. The quality control samples, QCL, QCM and QCH were analyzed for all stability studies.

\section{Short term storage stability}

Three replicates of each QC samples (stability sample) were left on the bench top (at room temperature) for a time exceeding the maximum period of time expected for routine sample preparation $(6 \mathrm{~h})$ then a calibration curve was freshly processed and analyzed with all stability samples in a single run. The comparison was done between the stability samples the fresh ones at equivalent concentration.

\section{Post preparative stability}

The stability samples processed then stored in the thermostated auto sampler $\left(25^{\circ} \mathrm{C}\right)$ for $20 \mathrm{~h}$, the expected longest storage times of the samples in autosampler before injection. A calibration curve was freshly processed and analyzed with all stability samples in a single run. The stability samples were compared to the fresh ones at equivalent concentration.

\section{Freeze and thaw stability}

Stability of captopril was assessed in plasma samples subjected to three freeze-thaw cycles of $-85^{\circ} \mathrm{C}$ during $24 \mathrm{~h}$. The stability samples were prepared and subjected to three cycles of freeze-thaw operations in three consecutive days. After the third cycle the samples were analyzed against calibration curve of the day. The comparison was done between the mean concentration calculated for the samples subjected to the cycles and the fresh ones at equivalent concentration.

\section{Long-term stability}

Three replicates of each QC sample were subjected to freeze storage $\left(-85^{\circ} \mathrm{C}\right)$ during the entire period covered by the bioequivalence study, i.e., from the first day of subjects sample collection up to the last day of sample analysis. Storage stability was determined by comparing sample concentration to the mean values obtained at first-day analysis. The values were calculated against calibration curve of the day and the mean values for the stored samples and nominal concentrations (fresh samples) were compared. To prove the stability of the samples, the difference 
between mean concentrations of the tested stability samples in various conditions and nominal concentrations should not exceed $\pm 15 \%$.

\section{RESULTS AND DISCUSSION}

Several liquid chromatographic methods were applied for determination of captopril in plasma using mass detection (Borges et al., 2006; Chik et al., 2014; Du, 2007; Rezende et al., 2007; Salem et al., 2005; Vancea et al., 2009). The aim of the present work was to apply the most suitable conditions to obtain high throughput method that can be applied for the analysis of captopril in plasma samples obtained from a bioequivalence study. Therefore protein precipitation was used for sample pretreatment where the time required $(8.5 \mathrm{~min}$.) was shorter than that used by Vancea et al (Vancea et al., 2009). The total chromatographic run time (3 min.) is also reasonable when compared to the reported chromatographic method (Vancea et al., 2009). To determine captopril in human plasma after a single dose of $50 \mathrm{mg}$, it was necessary to develop a bioanalytical method with LLOQ (10 $\mathrm{ng} / \mathrm{mL})\left(5 \%\right.$ of its $\left.\mathrm{C}_{\max }\right)$ to be able to determine the concentration of captopril from the first time interval till the elimination phase to draw the complete plasma concentration time curve (Guideline, 2011). It was better to use MS/MS detection, as MS/MS methods provide improved sensitivity for such small concentration. LCMS/MS using the MRM is a powerful technique for pharmacokinetic studies since it provides sensitivity and selectivity required for bioanalytical methods where foreign ions are expected to be present in the bio samples. Thus, the MRM technique was chosen for the method development. The parameters of the MRM presented in Table 1 were chosen after method optimization to give the maximum response for the analyte. The product ion mass spectra, and fragmentation patterns, of captopril and the IS are illustrated in Fig. 2.
Due to the presence of the free reactive $-\mathrm{SH}$ group in captopril, it was preferred to use the second approach described previously in the introduction section to protect the $-\mathrm{SH}$ group during the preparation and analysis steps. DTT was used to revert the converted disulphides dimmer (or conjugates) into captopril, as well as to prevent the formation of the disulphides dimmers during the sample preparation and analysis. Ideally, isotopically labeled internal standards for the analyte should be used, but these are not always commercially available and expensive. Upon trying the used extraction procedure for the extraction of rosuvastatin, good, precise and repeatable results were obtained. Moreover, the used mobile phase was suitable for rosuvastatin detection and quantitation. An efficient clean-up for biological samples to remove protein and potential interferences before analysis is an important step. In the present study, protein precipitation method was tested as it is the simplest, fastest and cheapest method for sample pre-treatment; it reduces the time of sample preparation and reduces the consumption of organic harmful liquids. Different protein precipitating agents such as acetonitril, perchloric acid and methanol were tried where methanol was found to be the best as it gave the clearest solution with low background noise, short retention time and high precise reproducible recovery both for analytes and IS. For the fast, best separation, UPLC was used and different mobile phases were tried where best separation was obtained on a C18 column by gradient elution using methanol: water (10: $90 \mathrm{v} / \mathrm{v}$ for $1 \mathrm{~min}$ then $95: 5 \mathrm{v} / \mathrm{v}$ till the end of the run). In order to obtain the maximum signal response and hence maximum detection sensitivity, formic acid $(0.1 \%)$ was added to the mobile phase.

The gradient chromatographic separation was performed at room temperature at a flow rate of $0.3 \mathrm{~mL} / \mathrm{min}$. Under these conditions the retention times were 2.04 and $2.3 \mathrm{~min}$ for captopril and the IS respectively. The total run time was $3 \mathrm{~min}$. enabling the analysis of 20 samples per one hour.

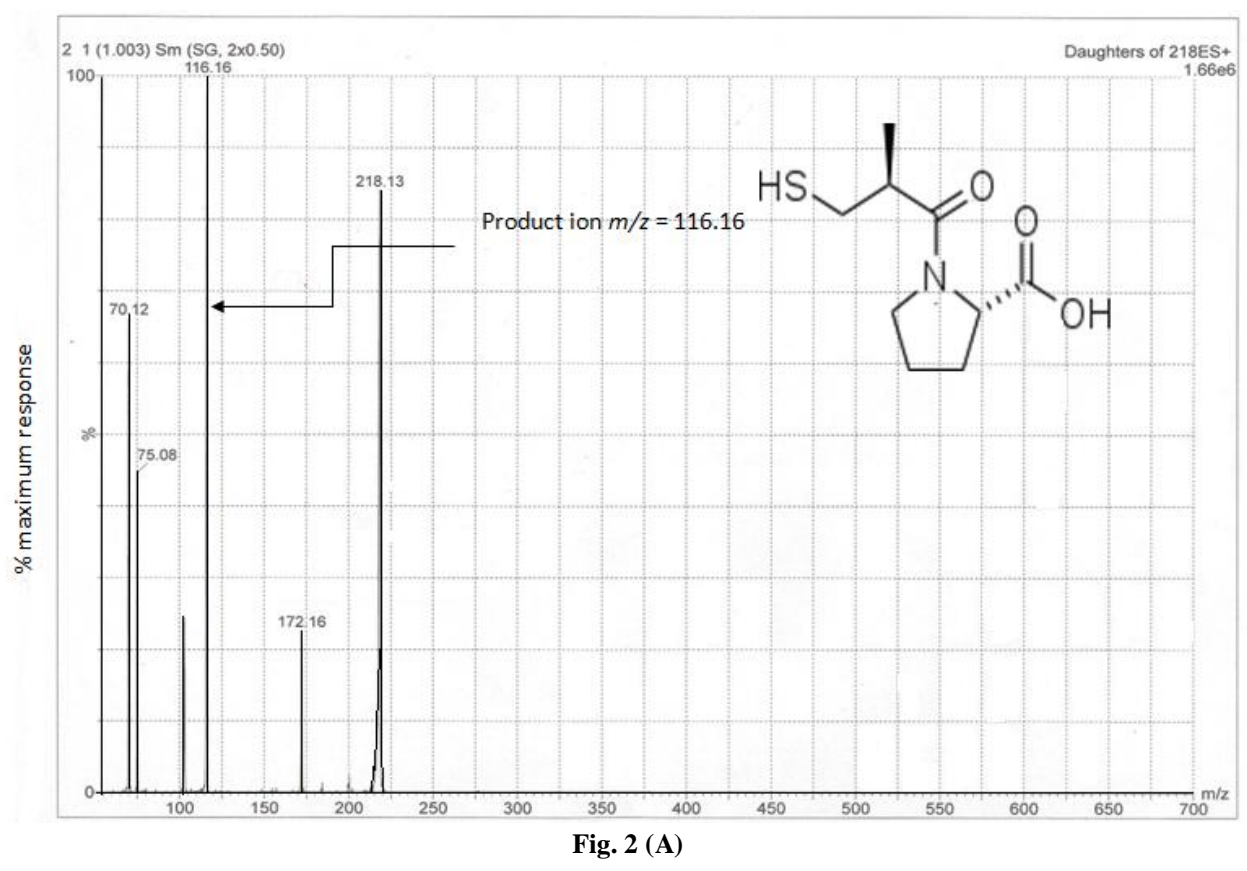




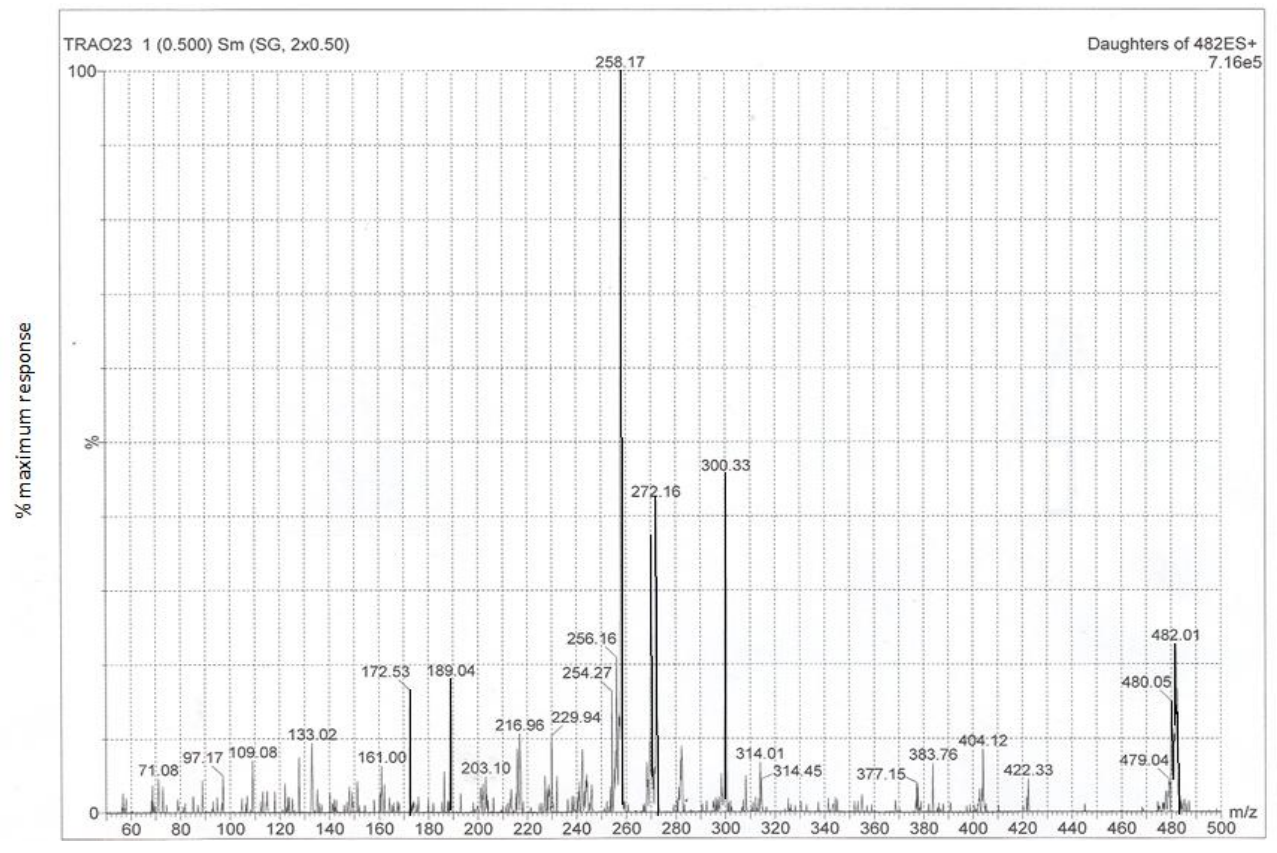

Fig. 2 (B)

Fig. 2: Full scan positive ion ESI product ion mass spectra and the proposed Pattern of fragmentation of (A) captopril and (B) rosuvastatin (IS).
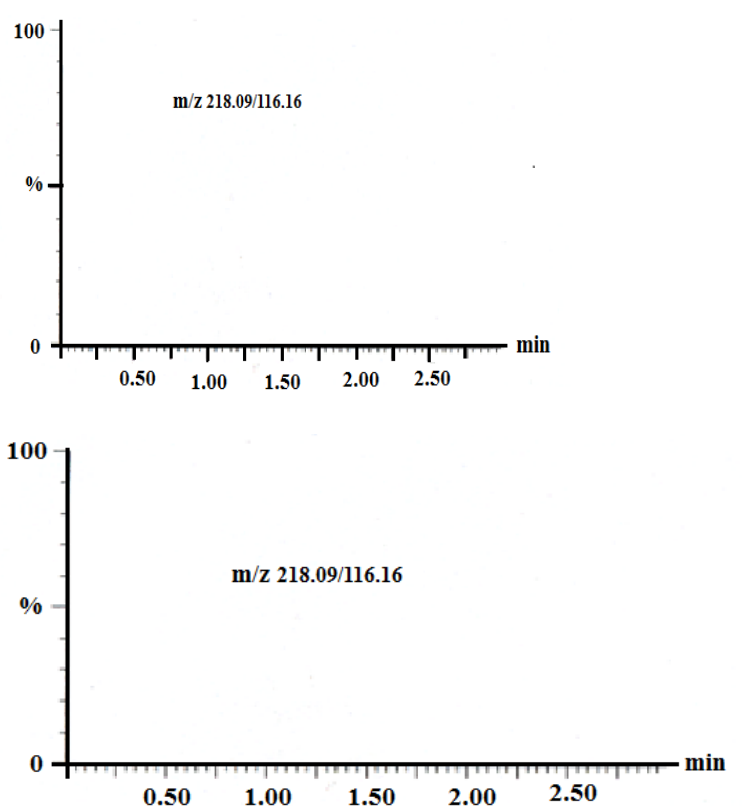

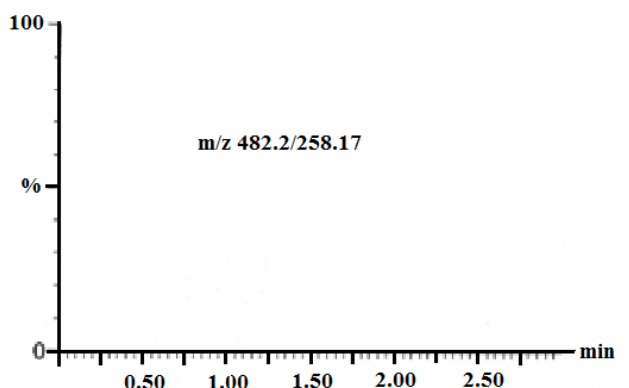

A
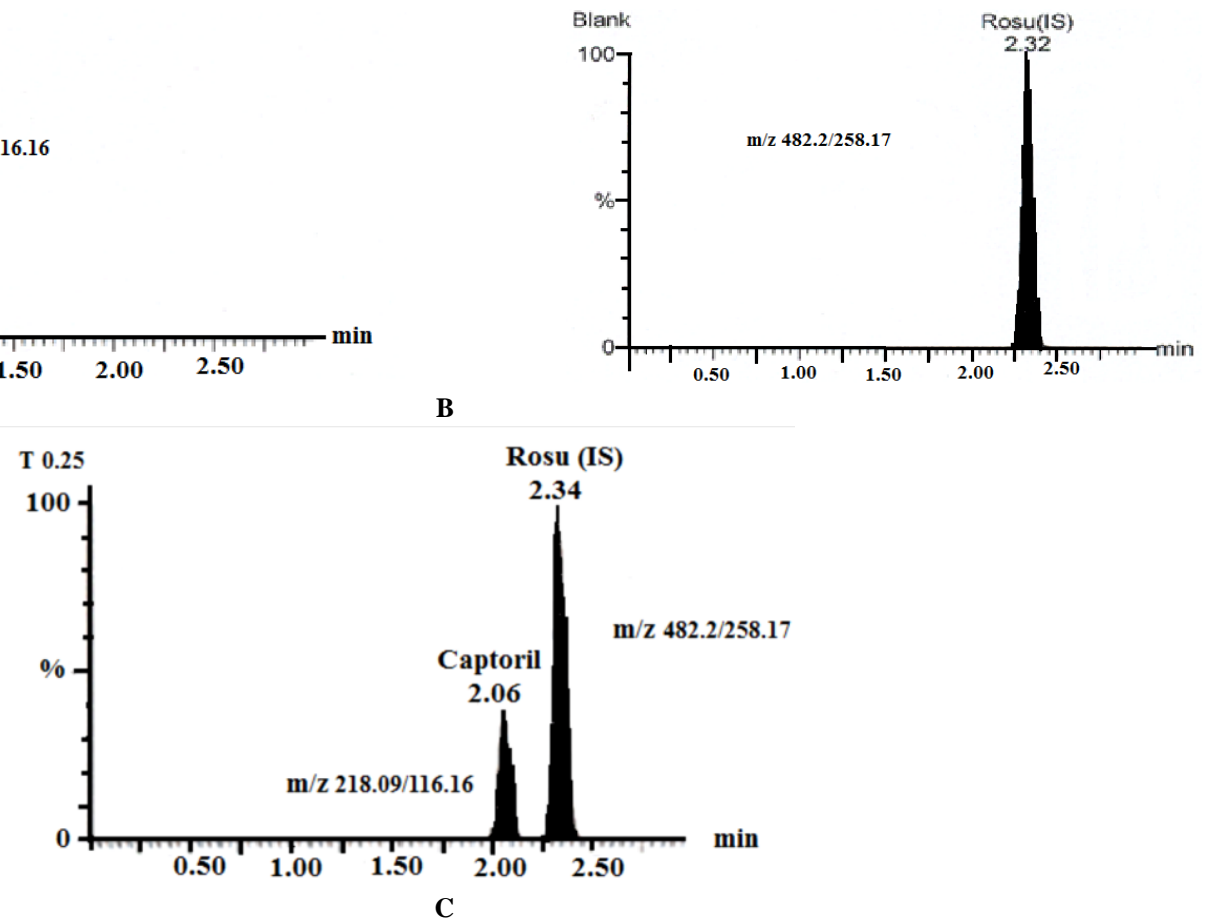

Fig. 3: MRM chromatogram of captopril and IS (A) blank plasma, (B) $3 \mu \mathrm{g} / \mathrm{ml}$ rosuvastatin (IS) and (C) An overlay of captopril and IS chromatograms for real plasma sample obtained from a subject at 15 min post dosing (concentration determined was $445.6 \mathrm{ng} / \mathrm{mL}$ ). 


\section{Method performance and validation Selectivity}

The LC-MS/MS method is highly selectivity because only the fragments derived from the precursor ion of the analytes of interest are monitored. The selectivity of the method was examined by analyzing ( $n=6)$ blank human plasma extract (Fig. 3(A)) and an extract spiked only with the IS (Fig. 3(B)). As shown in Fig. 3(A), no significant interference in the blank plasma was observed from endogenous substances in drug-free human plasma at the retention time of the analyte. Similarly, Fig. 3(B) shows the absence of direct interference from the IS to the MRM channel of the analyte. Furthermore, blank plasma samples from each subject were run before unknown sample quantification, to insure a clear chromatogram. The MRM chromatogram obtained from an extracted plasma sample of a healthy subject who participated in a bioequivalence study conducted on 24 subjects is presented in Fig. 3 (c). Captopril was identified and was quantified as $445.6 \mathrm{ng} / \mathrm{mL}$.

\section{Linearity of calibration curve and lower limit of quantification}

The nine-point (non-zero standards) calibration curve was linear over the concentration range $10-2000 \mathrm{ng} / \mathrm{mL}$. The linearity was evaluated by calculating the correlation coefficient and by evaluating the back caculated concentrations of the calibration standards. The mean $( \pm$ S.D.) linear regression equation of: $y=0.0009( \pm 0.00005) X-0.005( \pm 0.001)$ was obtained, where $\mathrm{y}$ is the peak area ratio of the analyte to the IS and $\mathrm{X}$ is the concentration of the analyte.

The mean correlation coefficient of the calibration curves generated during the validation was $0.9975 \pm 0.002$; Table 2 summarizes the calibration curve results.

Table 2: Precision and accuracy data of back-calculated concentrations of calibration samples for captopril in human plasma.

\begin{tabular}{ccccc}
\hline $\begin{array}{c}\text { Concentration } \\
\text { added }\end{array}$ & $\begin{array}{c}\text { Concentration Found } \\
(\mathbf{n g} / \mathbf{m L} \mathbf{)})\end{array}$ & Precision & Accuracy \\
\hline (ng/mL) & mean $(\mathbf{n = 6})$ & SD & CV\% & \% nominal \\
\hline 10 & 10.87 & 1.16 & 10.69 & 108.73 \\
25 & 27.54 & 1.32 & 4.79 & 110.18 \\
125 & 109.4 & 3.3 & 3.02 & 87.52 \\
250 & 229.36 & 8.79 & 3.83 & 91.74 \\
500 & 484.7 & 33.57 & 6.93 & 96.94 \\
750 & 787.08 & 25.65 & 3.26 & 104.94 \\
1000 & 1071.85 & 63.04 & 5.88 & 107.19 \\
1500 & 1527.47 & 85.8 & 5.62 & 101.83 \\
2000 & 1985.93 & 67.65 & 3.41 & 99.3 \\
\hline
\end{tabular}

The LLOQ is defined as the lowest concentration in the standard curve that can be measured with acceptable accuracy and precision, and was found to be $10 \mathrm{ng} / \mathrm{mL}$ in human plasma with an accuracy of $106.421 \%$ and precision of $5.583 \%$. Sufficient sensitivity was observed for a $10-\mu \mathrm{L}$ injection volume with signal to noise ratio of 290 (given by the instrument) at the retention time of the analyte. Under the present LLOQ, the captopril concentration could be determined in plasma samples up to the elimination phase of captopril (after about 7 half lives) after oral administration of $50 \mathrm{mg}$ captopril tablets.

\section{Accuracy and precision measurement}

Intra-day precision and accuracy of the assay were measured for captopril and IS at each QC level (30.0, 800.0 and $1600.0 \mathrm{ng} / \mathrm{ml}$ ). Method intra-day precision (\% CV) and accuracy ranged from 0.680 to $1.26 \%$, and 88.54 to $100.35 \%$, respectively. Method inter-day precision (\% CV) and accuracy ranged from 2.72 to $5.73 \%$, and 89.48 to $108.89 \%$, respectively, as presented in Table 3. These results were within the acceptance criteria for precision and accuracy, i.e., deviation values were within $\pm 15 \%$ of the nominal values.

Table 3: Intra and Interday accuracy and precision for determination of captopril in human plasma.

\begin{tabular}{ccccc}
\hline $\begin{array}{c}\text { Nominal } \\
\text { concentration }\end{array}$ & \multicolumn{2}{c}{ Intraday $(\mathbf{n}=6)$} & \multicolumn{2}{c}{$\begin{array}{c}\text { Interday }(\mathbf{n}=6 / \text { day }) \\
\text { 3days }\end{array}$} \\
\hline$(\mathbf{n g} / \mathbf{m L})$ & $\begin{array}{c}\text { Accuracy } \\
(\%)\end{array}$ & $\begin{array}{c}\text { Precision } \\
(\mathbf{C V} \%)\end{array}$ & $\begin{array}{c}\text { Accuracy } \\
(\%)\end{array}$ & $\begin{array}{c}\text { Precision } \\
(\mathbf{C V} \%)\end{array}$ \\
\hline 30.000 & 88.540 & 0.707 & 89.48 & 2.72 \\
800.000 & 100.350 & 0.680 & 108.00 & 5.48 \\
1600.000 & 100.260 & 1.260 & 108.89 & 5.73 \\
\hline
\end{tabular}

Table 4: Stability data of captopril under different conditions.

\begin{tabular}{lcc}
\hline Sample concentration & $\begin{array}{c}\text { Concentration } \\
\text { found }\end{array}$ & $\begin{array}{c}\text { \% Deviation } \\
\text { *fom }\end{array}$ \\
\hline (ng/mL) & (ng/mL) & $\begin{array}{c}\text { fresh sample } \\
\text { concentration }\end{array}$ \\
\hline Fresh samples & 31.29 & \\
30.00 & 819.83 & \\
800.00 & 1614.42 & \\
1600.00 & & \\
\hline Short term stability (6h at room temp) & 29.73 & \\
\hline 30.00 & 795.39 & 2.98 \\
800 & 1611.32 & 0.19 \\
1600 & & 1.60 \\
\hline Post preparative stability (12 h) & 30.79 & 2.24 \\
\hline 30 & 801.43 & 0.02 \\
800 & 1614.06 & 0.38 \\
1600 & & 4.11 \\
\hline Long term stability (-85oC for 60 days) & 31.17 & 2.90 \\
\hline 30 & 786.11 & 1.47 \\
800 & 1567.58 & 0.44 \\
1600 & & 0.76 \\
\hline Freeze- thaw cycles (three cycles) & 30.83 & \\
\hline 30 & 816.19 & \\
800 & 1602.17 & \\
1600 & & \\
\hline$\%$ deviation = 100 x (Stability sample - Fresh sample/ Fresh sample). & \\
\hline
\end{tabular}

\section{Recovery of captopril}

Recoveries for both captopril and IS were evaluated as described in the experimental section. The average recoveries of captopril from spiked plasma samples were $89.46 \pm .2 .221 \%$, $92.653 \pm .0 .657 \%$ and $92.407 \pm .1 .346 \%$ for 30,800 and 1600 $\mathrm{ng} / \mathrm{mL}$ respectively. The recovery of the IS was $84.1 \pm .1 .0 \%$ at the concentration used in the method $(3 \mu \mathrm{g} / \mathrm{mL})$. Recoveries of the analyte and IS were good, consistent, precise and reproducible.

\section{Assessment of stability}

Captopril was found to be stable at room temperature for 6 hours which is the maximum time for sample preparation. No significant degradation of captopril and IS was observed when the 
extracted samples were kept in the autosampler at $25^{\circ} \mathrm{C} 12$ hours. Upon three freeze/thaw cycles, almost no difference was observed in the concentrations of QC samples in comparison to the freshly prepared samples. Captopril was also found to be stable under the long term storage conditions $\left(-85^{\circ} \mathrm{C}\right)$ for at least 60 days which is long enough to cover the whole study duration (Table 4). The stability of the stock solutions prepared in methanol was tested at $10^{\circ} \mathrm{C}$ for seven days. The recovery was $97.09 \pm 0.153 \%$ and $98.10 \pm 0.320 \%$ for captopril and IS, respectively indicating suitable stability during a week. Working solutions were prepared daily just before spiking for both the calibration curve and the QC samples.

\section{APPLICATION}

The method was applied to analyze the samples of 24 healthy adult subjects who have participated in a Bioequivalence study of two tablet formulations of captopril. The study was a single oral dose, two-way randomized crossover design with a 7day washout period between the doses. The study was planned and performed according to the current GCP guidance. All subjects gave written informed consent and local ethics committee approved the protocol. At each period, each subject was administered a single dose of $50 \mathrm{mg}$ captopril tablet along with approximately $250 \mathrm{ml}$ of water after fasting for at least 12 hours. Regular standardized low-fat meals were provided $4 \mathrm{~h}$ after dose administration, and water intake was allowed at $2 \mathrm{~h}$ following drug administration. The subjects were monitored throughout the study and the formulations were considered to be well tolerated. The multiple blood samples were collected into the heparinized tubes at $0,0.25,0.5,0.75,1,1.25,1.5,2,2.5,3,4,6,8$ and 10 hours post dose. Five milliliters of venous blood were withdrawn from each volunteer. Blood samples were transferred immediately to heparinized tubes, centrifuged for $10 \mathrm{~min}$ at $3200 \times g\left(\right.$ at $4{ }^{\circ} \mathrm{C}$ ) and the separated plasma transferred to Eppendorf tubes and stored at $-80 \circ \mathrm{C}$ until the day of analysis. Plasma samples were processed as described above to determine the concentration of captopril. The mean plasma concentration-time curve from 24 subjects is shown in figure 4 after receiving an oral dose of captopril test and reference tablets. The corresponding bioequivalence parameters of captopril are summarized in Table 5.

Table 5: Summary of the pharmacokinetic parameters of captopril following the oral administration of one capozide TM 50/25 mg tablet (R) and one captopril-H 50/25 mg tablet (T).

\begin{tabular}{lll}
\hline $\begin{array}{l}\text { Pharmacokinetic } \\
\text { Parameter }\end{array}$ & $\begin{array}{l}\text { Capozide TM 50/25 mg } \\
\text { tablet }\end{array}$ & $\begin{array}{l}\text { Captopril-H 50/25 mg } \\
\text { tablet }\end{array}$ \\
\hline $\begin{array}{l}\mathbf{C}_{\max }(\mathbf{n g} / \mathbf{m L}) \\
\text { Mean } \pm \text { SD }\end{array}$ & $1032.22 \pm 160.00$ & $1037.43 \pm 151.42$ \\
Range & $782.51-1239.74$ & $769.07-1259.84$ \\
\hline $\mathbf{t}_{\max }(\mathbf{h r})$ & & \\
Median & 1.00 & $1 . .25$ \\
Mean \pm SD & $1.00 \pm 0.2$ & $1.1 \pm 0.2$ \\
Range & $0.8-1.3$ & $0.8-1.3$ \\
\hline AUC0-t (ng.hr/mL) & & \\
Mean \pm SD & $3287.51 \pm 875.81$ & $3316.47 \pm 849.35$ \\
Range & $1888.40-4787.56$ & $222.23-4743.45$ \\
\hline
\end{tabular}

\begin{tabular}{lll}
\hline AUC0- $\infty$ (ng.hr/mL) & & \\
Mean \pm SD & $3615.08 \pm 975.28$ & $3635.07 \pm 925.95$ \\
Range & $2047.83-5402.13$ & $2121.35-5281.68$ \\
\hline
\end{tabular}

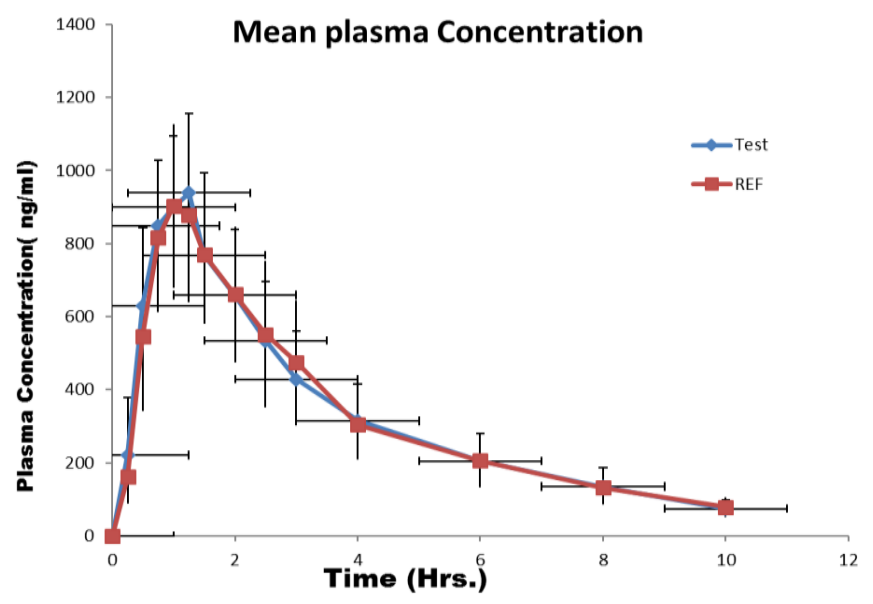

Fig. 4: Mean Plasma Concentration Time Curve of Captopril Following the Oral Administration of One Capozide TM 50/25 mg tablet(R) and One Captopril-H 50/25 mg tablet (T) to 24 Volunteers.

\section{CONCLUSIONS}

The particular LC-MS/MS assay shown with this report is simple, fast and sensitive pertaining to determination of captopril in human plasma. This method was fully validated according to the recent FDA guidelines. The method showed precise recovery for both captopril and the internal standard. The method furnished beneficial linearity and being trusted to guide pharmacokinetic study in humans as the desired sensitivity of captopril was achieved with an LLOQ of $10 \mathrm{ng} / \mathrm{mL}$. Many variables related to the electrospray reproducibility were optimized for both precision and sensitivity to obtain these results. The simplicity of the method, and using protein precipitation and sample turnover rate of 3.0 min per sample, make it an attractive procedure in high-throughput bioanalysis of captopril. The validated method allows quantification of captopril in the 10-2000 $\mathrm{ng} / \mathrm{mL}$ range

\section{ACKNOWLEDGEMENTS}

The authors gratefully acknowledge CARAS Laboratories (Faculty of Pharmacy, Cairo, Egypt) for providing essential services to carry out this study. In addition, the authors are grateful to Dr. Ihab Rasmy, Associate Professor of Pharmaceutics, Faculty of pharmacy, Cairo University, for carrying out the pharmacokinetics calculations.

\section{Financial support and sponsorship: Nil.}

Conflict of Interests: There are no conflicts of interest.

\section{REFERENCES}

Aykin N, Neal R, Yusof M, Ercal N. Determination of captopril in biological samples by high-performance liquid chromatography with ThioGlo $^{\text {TM}} 3$ derivatization. Biomed. Chromatogr., 2001; 15:427-432. 
Bald E, Sypniewski S. Determination of thiol drugs in pharmaceutical formulations as their S-pyridinium derivatives by highperformance liquid chromatography with ultraviolet detection. Fresenius J. Anal. Chem., 1997; 358:554-555.

Bald E, Sypniewski S, Drzewoski J, Stepien M. Application of 2-halopyridinium salts as ultra-violet derivatization reagent and solid phase extraction for determination of captopril in human plasma by HPLC. J. Chromatogr. B: Biomed. Sci. Appl., 1996; 681:283-289.

Borges NCC, Heleno MAG, Moreno RA. Comparative bioavailability of two formulation of captopril in healthy volunteers after the administration of a single dose. Revista Brasileira de Medicina,2006; 63:518-522. (In Portugulese)

Chik Z, Deril NM, Didi EMH, Basu RC, J. Ratnasingam J. A bioequivalence comparison of two captopril formulations ( $25 \mathrm{mg}$ Tablets): An open-label, randomized, two-treatment, two-way crossover study in healthy volunteers. J. Bioequiv. Availab., 2014; 6:80-85.

Ding J., Zhang B, Li H, Liu Y, Deng H. HPLC Determination of Captopril in Human Plasma with Pre-column Derivation and Solidphase Extraction and Studies on Its Pharmacokinetic and Relative Bioavailability. J. Chin. Pharm. Sci., 2001; 10:52-156.

Du M. Determination of Captopril in Human Plasma by Liquid Chromatography/ Tandem Mass Spectrometry. Anal. Lett., 2007; 40:3245-3255.

Duchin KL, McKinstry DN, Cohen AL, Migdalof BH. Pharmacokinetics of captopril in healthy subjects and in patients with cardiovascular diseases. Clin. Pharmacokinet., 1988; 14:241-259.

FDA Guidance for Industry Bioanalytical Method Validation, U.S. Department of health and human services, Food and Drug Administration, Center for Drug Evaluation and Research (CDER), In 2001.

Foroutan SM, Zarghi A, Shafaati AR, Khoddam A. Bioequivalance studies of two Iranian generic formulations of Captopril in healthy volunteers Arch. Iran. Med., 2003; 6:44-48.

Guideline on bioanalytical method validation, European medicines agency, Science medicines healthy, 2011.

Hadjmohammadi MR, Kamel K, Khajooeinezhad F. Determination of captopril in human plasma with precolumn derivatization using solid phase extraction and HPLC. J. Iran. Chem. Soc., 2008; 5:324327.

Huang T, He Z, Yang B, Shao L, Zheng X, Duan G. Simultaneous determination of captopril and hydrochlorothiazide in human plasma by reverse-phase HPLC from linear gradient elution. J. Pharm. Biomed. Anal.,2006; 41:644-648.

Jankowski A, Skorek A, Krzysko K, Zarzycki PK, Ochocka RJ, Lamparczyk H. Captopril: determination in blood and pharmacokinetics after single oral dose. J. Pharm. Biomed. Anal.,1995; 13:655-660.

Klein J, Colin P, Scherer E, Levy M, Koren G. Simple measurement of captopril in plasma by high-performance liquid chromatography with ultraviolet detection. Ther Drug Monit., 1990; 12:105-110.
Kok RJ, Visser J, Moolenaar F, Zeeuw D, Meijer DKF. Bioanalysis of captopril: two sensitive high-performance liquid chromatographic methods with pre- or postcolumn fluorescent labeling. J. Chromatogr. B: Biomed. Sci. Appl., 1997; 693:181-189.

Li K, Tan L, Zhou JA. HPLC Determination of Captopril in Human Plasma and Its Pharmacokinetic Study. Biomed Chromatogr., 1996; 10:237-239.

Physicians' Desk Reference (PDR), 2003, Medical Economics. fifty-seventh ed.; Montvale: NJ, USA, 2197-2200.

Rezende KR, Mundim IM, Teixeira LS, Souza WC, Ramos DR, Cardoso CRF, Souza IC, Gratao MZ, Bellorio KB. Determination of captopril in human plasma, using solid phase extraction and highperformance liquid chromatography, coupled to mass spectrometry: application to bioequivalence study. J. Chromatogr. B: Biomed. Sci. Appl., 2007; 850:59-67.

Salem II, Saif WA, Jmeian Y, Tamimi JIA. A selective and rapid method for the quantification of captopril in human plasma using liquid chromatography/selected reaction monitoring mass spectrometry. J. Pharm. Biomed. Anal., 2005; 37:1073-1080.

Srinivas RN, Mamidi R. Bioanalytical considerations for compounds containing free sulfhydral groups. Biomed. Chromatogr.,2003; 17:285-291

Sultan N, Naveed S, Arayne MS. RP-HPLC Method for the Simultaneous Determination of Captopril and H2-Receptor Antagonist: Application to Interaction Studies. Med. chem., 2013; 3:183-187.

Sypniewski S, Bald E. Determination of captopril and its disulphides in whole human blood and urine by high-performance liquid chromatography with ultraviolet detection and precolumn derivatization. J. Chromatogr. A, 1996; 729:335-340.

Tache F, Farca A, Medvedovici A, David V. Validation of a LC-fluorescence method for determination of free captopril in human plasma, using a pre-column derivatization reaction with monobromobimane. J. Pharm. Biomed. Anal., 2002; 28:549-557.

Vancea S, Imre S, Donáth-Nagy G, Béla T, Nyulas M, Muntean T, Borka-Balás R. Determination of free captopril in human plasma by liquid chromatography with mass spectrometry detection. Talanta, 2009; 79:436-441.

\section{How to cite this article:}

Elzanfaly ES, Merey HA. A Liquid Chromatography/Tandem Mass Spectrometric Method for Determination of Captopril in Human Plasma. Application to a Bioequivalence Study. J App Pharm Sci, 2017; 7 (02): 008-015. 